\title{
Chromosomal instability associated with adverse outcome: a case report of patient with Nijmegen breakage syndrome and rapidly developed T-NHL with complex karyotype
}

\author{
Monika Włodarczyk ${ }^{1 *}$ (D) and Monika Lejman ${ }^{1,2}$ (D)
}

\begin{abstract}
Background: Nijmegen breakage syndrome (NBS) is a rare genetic disorder inherited in an autosomal recessive pattern associated with an increased risk of developing lymphoproliferative disorders, mainly non-Hodgkin lymphoma (NHL) and acute lymphoblastic leukemia (ALL). NBS patients are 50 times more likely to develop malignancy than healthy controls. Moreover, in NBS, mortality rate from cancers, mainly lymphomas, is the highest among all diseases associated with excessive fragility of chromosomes.

Case presentation: This work presents a patient previously diagnosed with Nijmegen breakage syndrome who rapidly developed T-NHL despite of constant medical supervision. Cytogenetic karyotype and microarray tests revealed complex aberrations, indicating enhanced chromosomal instability. Despite initial steroid therapy, the patient passed away due to multiorgan failure.

Conclusions: The lack of well-established diagnostic procedures in NBS patients make it difficult to determine any therapeutic target or predictive marker. Moreover, anticancer treatment is the biggest challenge in NBS patients due to therapy-related toxicity and immunodeficiency. Our case indicates the importance of identifying parameters useful in prognosis of disease outcome, as main risk factor affecting overall survival in NBS patients is an extremely high incidence of malignancy development.
\end{abstract}

Keywords: Nijmegen breakage syndrome, Non-Hodgkin lymphoma, Gene, FISH, Microarray

\section{Introduction}

Nijmegen breakage syndrome (NBS) is a rare genetic disorder inherited in an autosomal recessive pattern associated with an increased risk of developing lymphoproliferative disorders, mainly non-Hodgkin lymphoma (NHL) and acute lymphoblastic leukemia (ALL) $[1,2]$.

\footnotetext{
* Correspondence: m.wlodarczyk214@gmail.com

'Laboratory of Genetic Diagnostics, Medical University of Lublin, Lublin, Poland

Full list of author information is available at the end of the article
}

Moreover, NBS patients are 50 times more likely to develop malignancy than healthy controls [3]. The disease is caused by mutations in NBS1 gene located on chromosome 8q21. The most commonly observed NBS mutation, affecting approximately $90 \%$ of all NBS cases, is 657_661del5 in exon 6 of $N B N$ gene $[1,4]$. Furthermore, most of NBS patients are of Slavic origin, thus this particular alteration is called Slavic mutation [4]. NBS seems to occur worldwide, but the majority of cases were reported among Central European and Eastern

(C) The Author(s). 2020 Open Access This article is licensed under a Creative Commons Attribution 4.0 International License, which permits use, sharing, adaptation, distribution and reproduction in any medium or format, as long as you give appropriate credit to the original author(s) and the source, provide a link to the Creative Commons licence, and indicate if changes were made. The images or other third party material in this article are included in the article's Creative Commons licence, unless indicated otherwise in a credit line to the material. If material is not included in the article's Creative Commons licence and your intended use is not permitted by statutory regulation or exceeds the permitted use, you will need to obtain permission directly from the copyright holder. To view a copy of this licence, visit http://creativecommons.org/licenses/by/4.0/. The Creative Commons Public Domain Dedication waiver (http://creativecommons.org/publicdomain/zero/1.0/) applies to the data made available in this article, unless otherwise stated in a credit line to the data. 
European populations (Poland, Czech Republic, Ukraine) with relatively high $(1 / 177)$ carrier frequency $[1,5-7]$.

Characteristic cellular features of the NBS include increased telomere loss and sensitivity to ionizing radiation, and chromosomal instability resulting from spontaneous chromosome aberrations, usually affecting locus on chromosomes 7 (T-cell receptor (TCR) gene cluster) and 14 (immunoglobulin heavy chain gene cluster) [4]. Among the clinical features of NBS are progressive microcephaly, dysmorphic facial features (including sloping forehead, prominent nose, small mandible, long philtrum), dysmorphic ears, mild growth retardation and immunodeficiency [5, 7]. In NBS, mortality rate from cancers, mainly lymphomas, is the highest among all diseases associated with excessive fragility of chromosomes $[8,9]$.

\section{Case report}

A 4-year-old boy was admitted to Department of Genetic Diagnostics due to microcephaly, mild growth retardation and dysmorphic facial features, such as sloping forehead, large ears and prominent nose. There were no comorbidities, as well as no significant findings in the patient's family history. To assess the somatic karyotype of patient culture of blood samples was performed under standard conditions of $37^{\circ} \mathrm{C}$ and $5 \% \mathrm{CO}_{2}$ in PB MAX Karyotyping Medium (Thermo Fisher Scientific, Waltham, MA, USA). To stop cell division at mitosis, a mitotic inhibitor (Colchicyne Solution $10 \mu \mathrm{g} / \mu \mathrm{l}$ in NBSS, Thermo Fischer Scientific, Waltham, MA, USA) was added to the cell culture. Then, Carnoy's solution (3:1 methanol:acetic acid) was used to fixation of cells. GTG band staining was performed and the karyotype of patient was assessed using Axio Imager.Z2 microscope (Zeiss, Oberkochen, Germany) and Applied Spectral Imaging (Carlsbad, CA, USA) software. The karyotype was described according to The International System for $\mathrm{Hu}-$ man Cytogenetic Nomenclature (ISCN). Cytogenetic analysis revealed normal karyotype, including no cytogenetic abnormalities involving chromosomes 7 and 14 . No chromosomal instability was found in any of the chromosomes, thus further analysis was performed using molecular techniques (Sanger method, ABI 3130, Applied Biosystem, MA, USA). The patient was diagnosed with Nijmegen breakage syndrome as genetic test confirmed homozygotic deletion c.657_661delACAAA in the $N B N$ gene.

After 2 years, the boy was admitted to the Department of Pediatric Hematology, Oncology and Transplantology, Medical University of Lublin, Poland, due to pneumonia. The boy reported pain lasting 3 weeks in the lower extremities and swollen submandibular nodes from a week. The patient's condition was defined as severe, as his examination revealed leukocytosis (white blood cells =
$50,000 / \mu \mathrm{l})$, lymphadenopathy and the presence of a tumor in the mediastinum. Myelogram presented 54\% blasts with T-NHL phenotype: TCR $\alpha / \beta-\mathrm{TCR} \gamma / \delta+$, CD45+, CD7+, cytCD3+, CD3+, CD19dim+, CD5dim+, CD2+, CD45RA+, CD45RO+, CD8+, CD33+, CD13+, CD117dim+, CD123dim+, CD16dim+, CD11c+. Ultrasound examination of the neck revealed lymph node conglomerates on both sides with reduced echogenicity and rounded shape. Lymph node biopsy was performed for histopathological examination, which showed hyperplasia of lymphoblastic morphology. Lymphoblastic cells revealed a positive expression of $\mathrm{CD} 3 \mathrm{c}, \mathrm{CD} 7, \mathrm{CD} 2, \mathrm{CD} 5$, CD4, CD8, moderate CD1a, TdT, CD56 and CALLA expression, and low CD79a expression. The result indicates cortical type of $\mathrm{T}$ cell lymphoblastic proliferation. The boy was diagnosed with stage IV T-NHL.

Moreover, 24-h unstimulated cell culture of bone marrow samples in standard conditions in MAX Bone Marrow Medium (Gibco, Thermo Fischer Scientific, Waltham, MA, USA) was performed to assess the somatic karyotype of patient. GTG band staining (Fig. 1a) and fluorescence in situ hybridization (FISH) test were performed with the use of probes: BCR/ABL1, KMT2A, ETV6/RUNX1 (Vysis, Abbot Molecular, Illinois, USA). The arrangement from ETV6/RUNX1 probe suggested ETV6 deletion (Fig. 1b). The arrangement of signals from other probes used was correct (Fig. 1c and d). Cytogenetic karyotype revealed many aberrations, but it was difficult to recognize and assess correct result from karyotype. Thus, microarray analysis was performed to improve genetic diagnosis (CytoScan HD, Applied Biosystems, part of Thermo Fischer Scientific, Waltham, MA, USA). Tests revealed additional alterations in the form of gained copies (4q32-q35, 6q22-q27, 10p11-p15) and loss regions (9p21-p24, 5q21-q35) (Fig. 2). Cytogenetic and microarray results were partially confirmed by FISH tests (Fig. 3). Finally cytogenetic result was the following: 45,XY,-1,dup(1)(p32p34),der(3)t(1;3)(q12;q22), $\operatorname{der}(5) \mathrm{t}(5 ; 10)(\mathrm{q} 21 ; \mathrm{p} 11), \operatorname{der}(9) \mathrm{t}(4 ; 9)(\mathrm{q} 32 ; \mathrm{p} 21), \operatorname{der}(11) \mathrm{t}(1 ; 11)$ (p32;p13),del(12)(p13),der(16)t(6;16)(q22;p13)[10]/46, $\mathrm{XY}$ [15] (Fig. 4 and Table 1). Despite initial steroid therapy, the patient passed away after 21 days due to multiorgan failure. Medical history of patient revealed that he was not exposed to radiation or any genotoxic agents since NBS diagnosis.

\section{Discussion and conclusions}

$N B N$ gene encodes for a protein (nibrin), which is a part of the Mre11/Rad50/NBN (MRN) nuclear protein complex. MNR function is crucial for DNA repair (especially double strand breaks, DSBs), recombination processes and checkpoint arrest $[10,11]$. Maintaining genome integrity is important for any organism, as the resulting modifications are associated with an increased risk of 


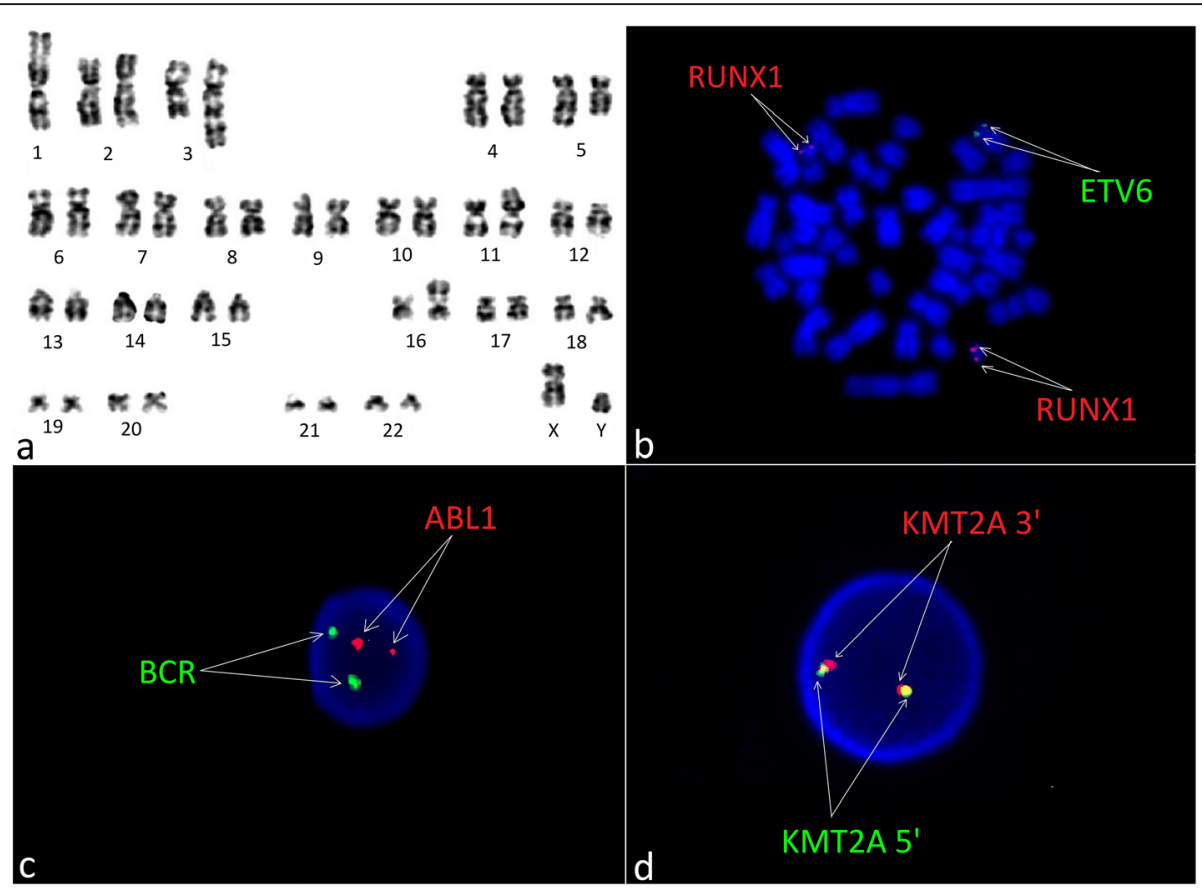

Fig. 1 Cytogenetic analysis of bone marrow cells at diagnosis of T-NHL in 6-year-old male. (a) The karyogram (GTG-banding) showing complex karyotype of the patient: 45,XY,-1, dup(1)(p32p34),der(3)t(1;3)(q12;q22),der(5)t(5;10)(q21;p11),der(9)t(4;9)(q32;p21),der(11)t(1;11)(p32;p13),del(12)(p13), $\operatorname{der}(16) t(6 ; 16)(q 22 ; p 13)[10] / 46, X Y[15](\mathbf{b}, \mathbf{c}, \mathbf{d})$ Results of FISH tests with probes: ETV6/RUNX1, BCR/ABL1 and KMT2A. FISH was performed on metaphases and interphase nuclei using probes (Cytocell Ltd., Oxford Gene Technology, Cambridge, United Kingdom) according to the manufacturer's recommendations. Images were captured by an Olympus BX41TF microscope equipped with a Jenoptik camera and analysed with Isis Software (MetaSystems)

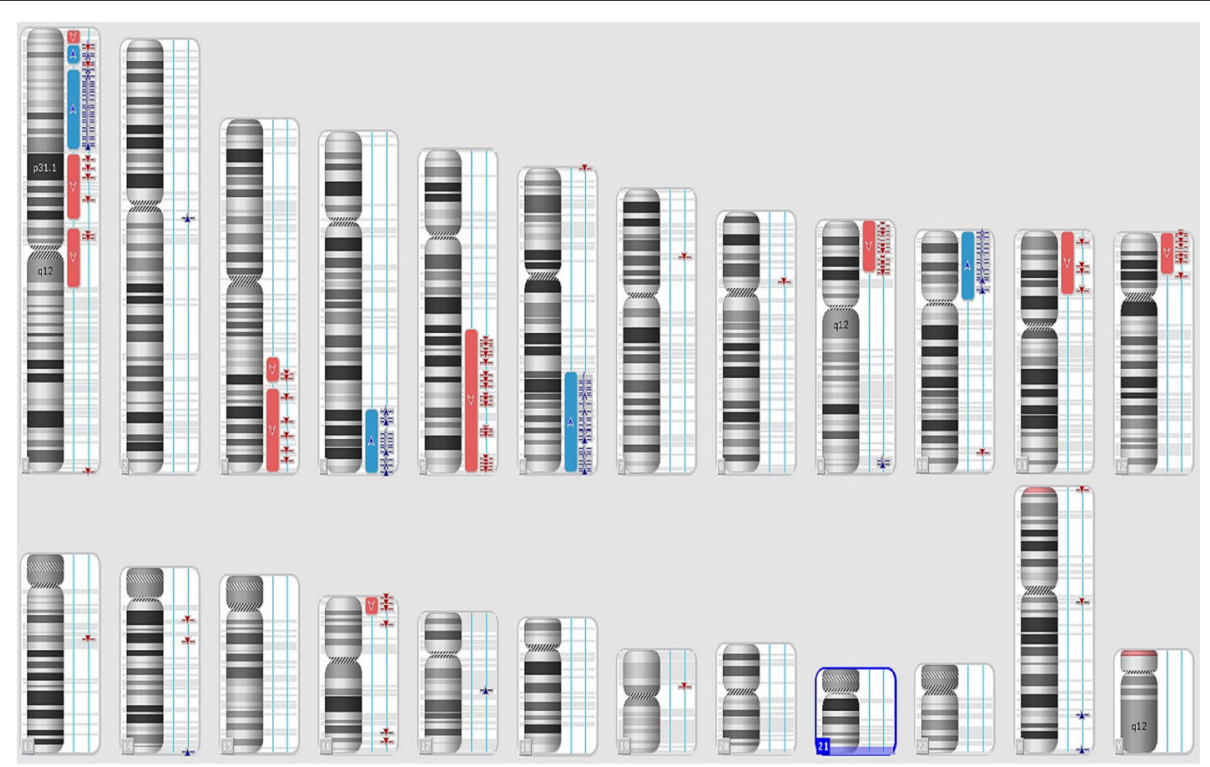

Fig. 2 Karyoview from microarray test and a scheme presenting chromosomal aberrations in patient. Microarray results revealing partial gains of overlapping regions on chromosomes 1p 8,931,529-67,365,806 bp (1p36.23-p31.3), 4q 155,500,158-190,957,473 bp (4q31.3-q35.2), 6q 115,144,178170,919,482 bp (6q22.1-q27) and 10p 100,026-38,258,848 bp (10p15.3-p11.1). Moreover, regions of overlap of deletions were also found on chromosomes 1 p 849,466-8,096,240 bp (1p36.33-p36.23) and 1 70,493,564-145,289,186 bp (1p31.12-q21.1), 5q 100,821,228-180,719,789 bp (5q21.1q35.3), $9 p$ 203,861-28,849,504 bp (9p24.3-p21.1), 11 p 230,615-35,363,338 bp (11p15.5-p13), 12p 173,786-22,885,159 bp (12p13.33-p12.1) and 16p 85,880-10,023,421 bp (16p13.3-p13.2). Asterisks correspond to deletion (red colour), duplication (blue colour) and loss of heterozygosity (purple colour) 


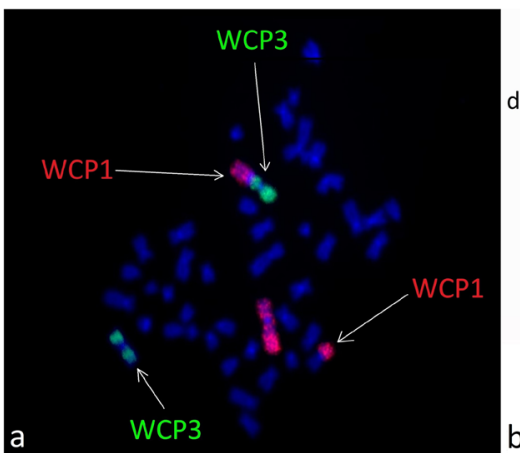

$a$
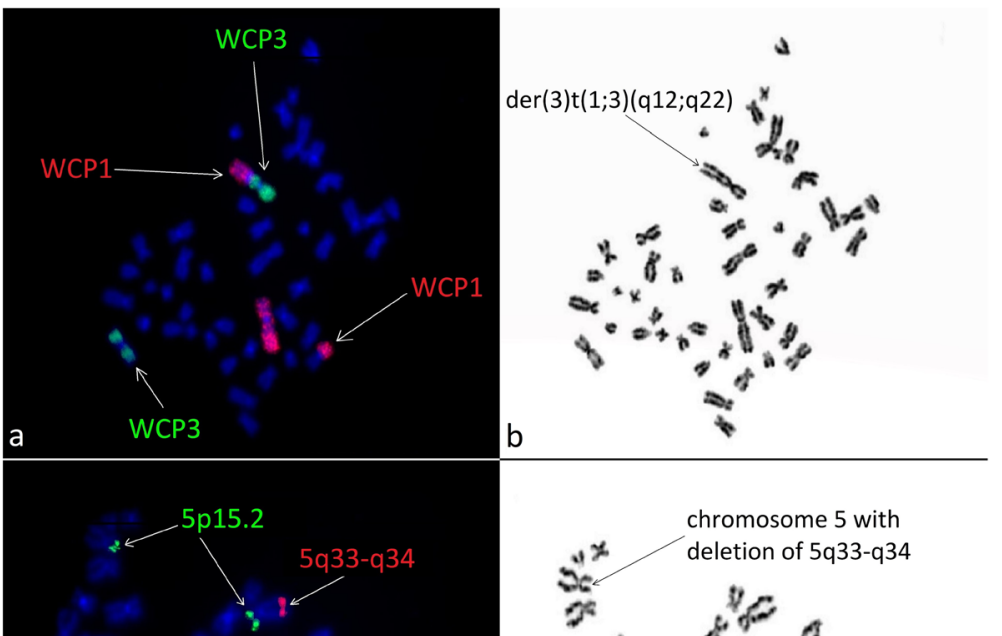

b
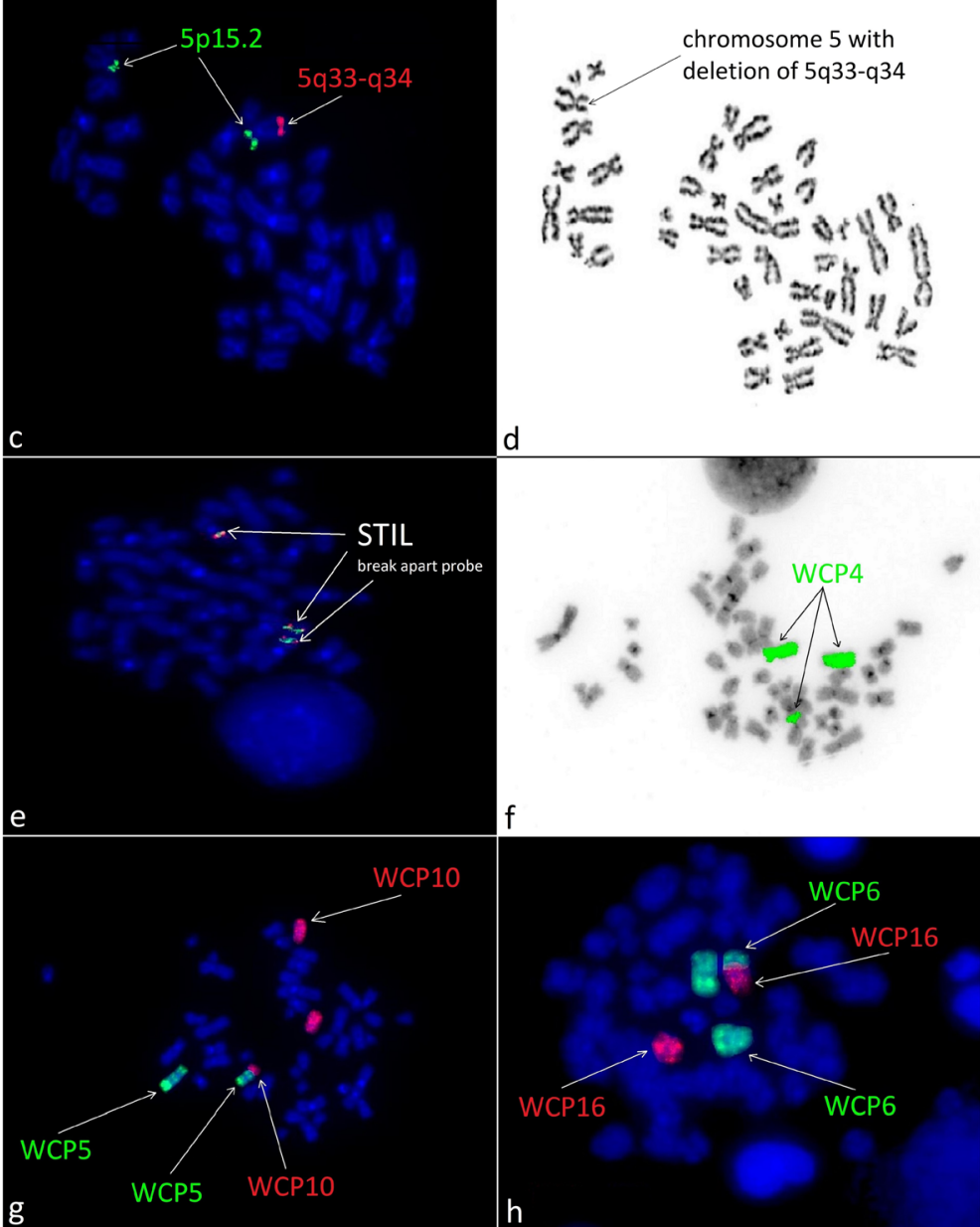

Fig. 3 Images of the FISH results revealing chromosomal aberrations. (a) Image of the FISH results with the whole chromosome painting (WCP) 1 and 3 probes (Cytocell Ltd., Oxford Gene Technology, Cambridge, United Kingdom) revealing t(1;3). (b) Chromosome analysis demonstrating derivative chromosomes $3 \operatorname{der}(3) t(1 ; 3)(q 12 ; q 22)$ and chromosome 1. (c) Image of the FISH results with the LSI CSF1R/D5S23, D5S721 Dual Color probe (Vysis, Abbot Molecular, Illinois, USA) revealing del(5q33-q34). (d) Chromosome analysis demonstrating abnormal chromosome 5 with deletion of 5q33-q34. (e) Image of the FISH results with the STIL Break Apart Probe (Empire Genomics, New York, USA) revealing STIL duplication. (f) Image of the FISH results with WCP4 probe (Cytocell Ltd., Oxford Gene Technology, Cambridge, United Kingdom) revealing t(4;9). (g) Image of the FISH results with WCP5 and WCP10 probes (Cytocell Ltd., Oxford Gene Technology, Cambridge, United Kingdom) revealing t(5;10). (h) Image of the FISH results with WCP6 and WCP16 probes (Cytocell Ltd., Oxford Gene Technology, Cambridge, United Kingdom) revealing t(6;16). Images were captured by an Olympus BX41TF microscope equipped with a Jenoptik camera and analysed with Isis Software (MetaSystems) 

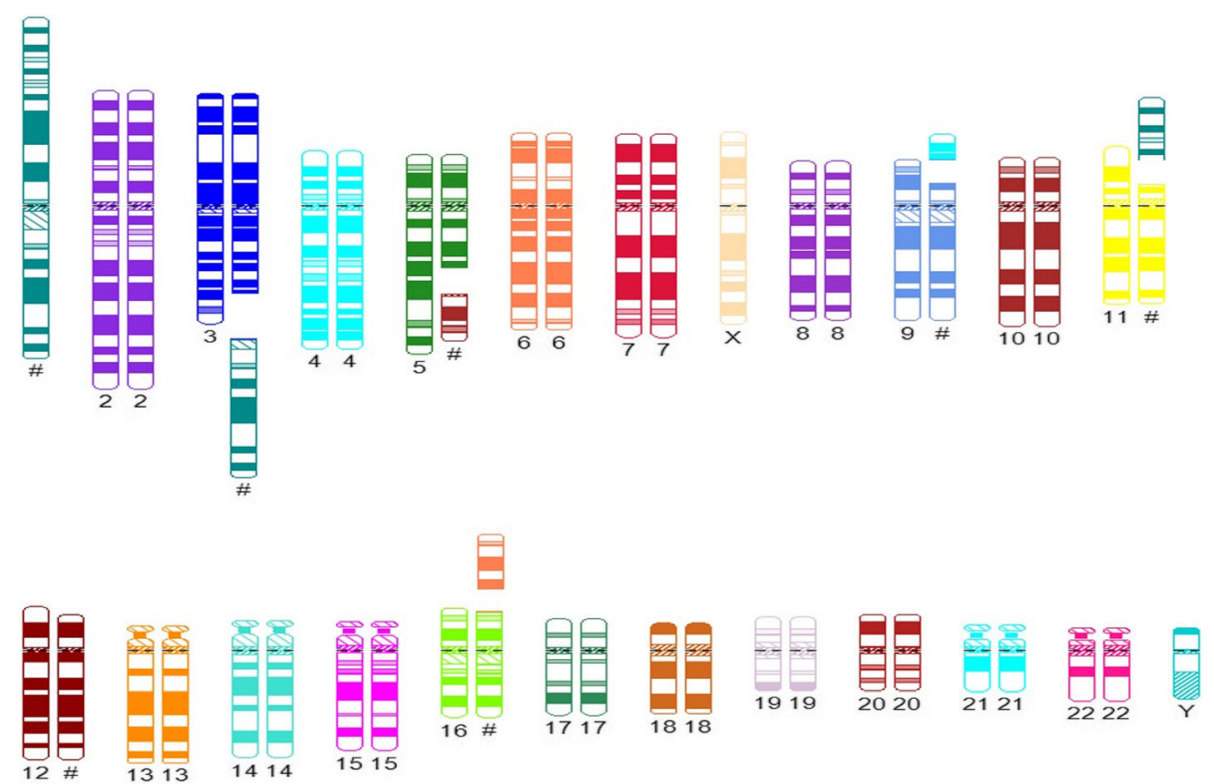

Fig. 4 The scheme of chromosomal aberrations in patient based on cytogenetic analysis, microarray tests and FISH results prepared using CyDAS software (http://www.cydas.org/OnlineAnalysis/, Duesseldorff, Germany). Hash represents derivative chromosomes

mutagenesis or carcinogenesis. In physiological conditions, double strand breaks are observed during DNA replication and meiotic recombination and in the processes of development of acquired immunity, as DNA DSBs occur in $V(D) J$ recombination during early $B$ and $\mathrm{T}$ cells differentiation and immunoglobulin class switch in mature B cells $[4,7]$.

$N B N$ mutation results in the fragmentation of nibrin into two nonfunctional parts: the $26 \mathrm{kDaN}$-terminal fragment and the $70 \mathrm{kDa}$ fragment, which retains the residual nibrin function [4]. Homozygous carrier of this mutation is associated with very early incidence of lymphomas, sarcomas and gliomas [4, 12, 13]. However, in Slavic populations, heterozygous carriers of the 657del5 mutation or the molecular variant R215W of the $N B N$ gene are often observed [1]. Population studies revealed that heterozygous carriers of the $N B N$ mutation are also at increased risk of developing lymphoproliferative cancers $[1,14]$.

Early diagnosis of NBS is crucial as it prevents from severe recurrent infections and unnecessary exposure to radiation during diagnostics procedures $[4,7]$. Due to the evolution of monoclonal gammopathy towards lymphoproliferative disorders in immunocompromised patients, monitoring of this parameter may be useful in determining the risk of developing malignancies in NBS patients [4]. Nevertheless, an improvement of immune system is needed to avoid further malignancies in patients with NBS and NHL.

From the moment of diagnosis, the patient was under constant medical supervision, and yet he developed advanced NHL as the consequence of extremely high chromosomal instability. Predisposition to malignancies, including lymphoid malignancies, is associated with chromosomal instability, as NBS patients have 250-fold risk of developing lymphomas $[1,4]$. Several non-specific symptoms, such as nodal enlargement and fever are thought to be connected with infection disease in NBS patients. Therefore, in NBS cases, advanced stages of lymphomas with multiorgan involvement are commonly observed [14, 15]. High incidence of lymphoma relapse, reduced treatment tolerance and delayed diagnosis of lymphoproliferative disorders in NBS patients are the cause of poor prognosis $[15,16]$. The distribution of $\mathrm{B}$ and $\mathrm{T}$ cell lymphoma in NBS patients was described in several studies to date [17]. We present for the first time a case of patient with NBS who developed T-NHL in relatively short time despite medical geneticists' supervision.

Chromosomal instability is associated with development of complex genetic markers in pre-cancer cells. Moreover, simultaneous acquisition of structural chromosomal aberrations and mutation enables tumor evolution, thus leading to poor outcome [18]. Despite the karyotype of NBS patients is generally normal, a lot of abnormalities in the form of aneuploidies, structural rearrangements and marker chromosomes may be observed in $10-60 \%$ of cells [4].

As NBN mutations affects maturation and function of $\mathrm{T}$ and $\mathrm{B}$ cells, NBS patients are high susceptible to infections, mostly involving respiratory system [4]. Moreover, due to bone marrow failure, severe infections, cardio- 


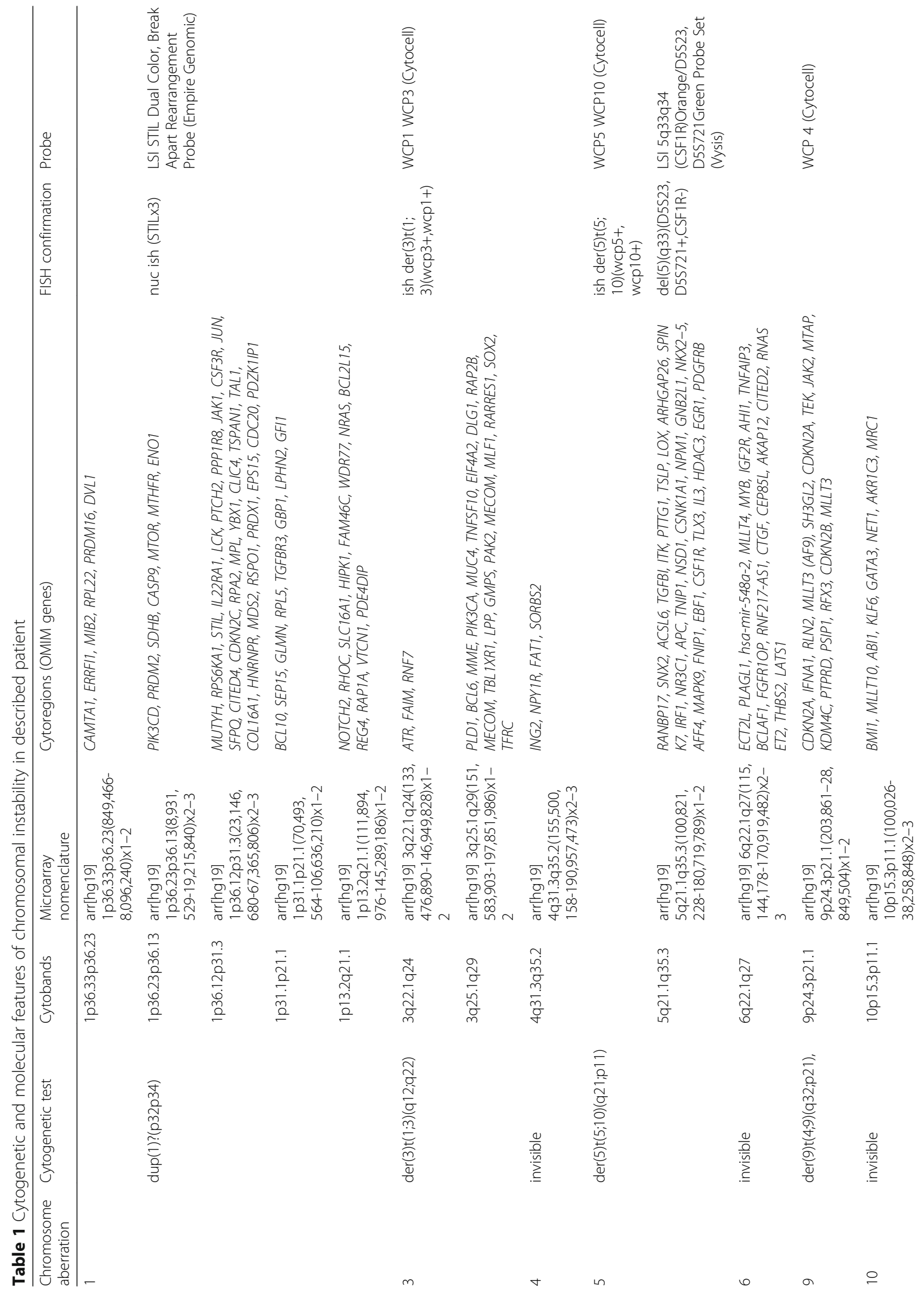




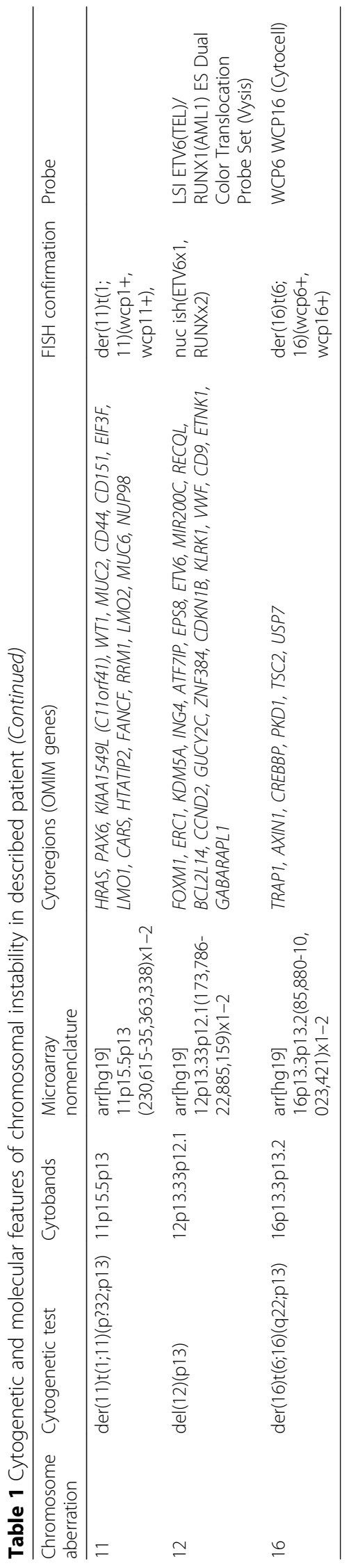


and nephrotoxicity, some forms of chemotherapy (including anthracyclines methotrexate and alkylating agents) and radiotherapy should be limited in the treatment of patients with NBS [4, 19]. Hematopoietic stem cell transplantation seems to be a last treatment option in NBS patients in whom standard chemotherapy protocols have failed [19].

The lack of well-established diagnostic procedure in NBS patients make it difficult to determine any therapeutic target or predictive marker [19]. Furthermore, anticancer treatment is the biggest challenge in NBS patients due to therapy-related toxicity and immunodeficiency.

The main risk factor affecting overall survival in NBS patients is an extremely high incidence of malignancy development. Most of NBS patients die in first decade of life due to unsuccessful cancer treatment, thus novel therapeutic intervention development is of great clinical importance $[4,19]$. Therefore, our case indicates the necessity of identifying parameters useful in the prognosis of NBS patients.

\section{Abbreviations}

NBS: Nijmegen breakage syndrome; NHL: Non-Hodgkin lymphoma; ALL: Acute lymphoblastic leukemia; TCR: T-cell receptor; FISH: Fluorescence in situ hybridization; DSB: Double strand breaks

\section{Acknowledgments}

We thank Dorota Winnicka for laboratory work.

\section{Authors' contributions}

$M L$ designed the research project. MW wrote the paper and was responsible for the acquisition of literatures for manuscript. ML and MW prepared final version of manuscript. The final manuscript was reviewed and approved by all authors.

\section{Funding}

Not applicable.

\section{Availability of data and materials}

The datasets generated and/or analysed during the current study are available in the Gene Expression Omnibus (GEO) repository, https://www. ncbi.nlm.nih.gov/geo/query/acc.cgi?acc=GSE148229.

\section{Ethics approval and consent to participate}

This study was approved by the ethics committee of Medical University of Lublin, Poland (committee's reference number: KNW/0022/KB1/153///16/17). Written, informed consent to participate was obtained from the patient's parents.

\section{Consent for publication}

Written, informed consent to publish was obtained from the patient's parents.

\section{Competing interests}

The authors declare that they have no competing interests.

\section{Author details}

'Laboratory of Genetic Diagnostics, Medical University of Lublin, Lublin, Poland. ${ }^{2}$ Department of Paediatric Haematology, Oncology and Transplantology, Medical University of Lublin, Lublin, Poland.
Received: 8 April 2020 Accepted: 17 July 2020

Published online: 20 August 2020

\section{References}

1. Chrzanowska KH, Piekutowska-Abramczuk D, Popowska E, Gładkowska-Dura M, Małdyk J, Syczewska M, et al. Carrier frequency of mutation 657del5 in the NBS1 gene in a population of polish pediatric patients with sporadic lymphoid malignancies. Int J Cancer. 2006;118(5):1269-74. https://doi.org/10 1002/ijc.21439.

2. Carney JP, Maser RS, Olivares H, Davis EM, Le Beau M, Yates JR 3rd, et al. The hMre11/hRad50 protein complex and Nijmegen breakage syndrome: linkage of double-strand break repair to the cellular DNA damage response. Cell. 1998;93(3):477-86. https://doi.org/10.1016/s0092-8674(00)81175-7.

3. Demuth I, Digweed M. The clinical manifestation of a defective response to DNA double-strand breaks as exemplified by Nijmegen breakage syndrome. Oncogene. 2007;26(56):7792-8. https://doi.org/10.1038/sj.onc.1210876.

4. Chrzanowska KH, Gregorek H, Dembowska-Bagińska B, Kalina MA, Digweed M. Nijmegen breakage syndrome (NBS). Orphanet J Rare Dis. 2012;7:13. https://doi.org/10.1186/1750-1172-7-13.

5. Kostyuchenko L, Makuch H, Kitsera N, Polishchuk R, Makarevych N, Akopian $H$. Nijmegen breakage syndrome in Ukraine: diagnostics and follow-up. Centr Eur J Immunol. 2009:34:46-52.

6. The I. Nijmegen breakage syndrome. The international Nijmegen breakage syndrome study group. Arch Dis Child. 2000;82(5):400-6. https://doi.org/10. 1136/adc.82.5.400

7. Varon R, Seemanova E, Chrzanowska K, Hnateyko O, PiekutowskaAbramczuk D, Krajewska-Walasek M, et al. Clinical ascertainment of Nijmegen breakage syndrome (NBS) and prevalence of the major mutation, 657del5, in three Slav populations. Eur J Hum Genet. 2000;8(11):900-2. https://doi.org/10.1038/sj.ejhg.5200554.

8. Wolska-Kuśnierz B, Gregorek H, Chrzanowska K, Piątosa B, Pietrucha B, Heropolitańska-Pliszka E, et al. Nijmegen breakage syndrome: clinical and immunological features, long-term outcome and treatment options - a retrospective analysis. J Clin Immunol. 2015;35(6):538-49. https://doi.org/10. 1007/s10875-015-0186-9.

9. Kawalec W, et al. Pediatria. Polska: PZWL; 2018. p. 1198-9. isbn:978-83200-5582-5.

10. Williams RS, Williams JS, Tainer JA. Mre11-Rad50-Nbs1 is a keystone complex connecting DNA repair machinery, double-strand break signaling, and the chromatin template. Biochem Cell Biol. 2007;85(4):509-20. https://doi.org/10. 1139/007-069.

11. Matsuura S, Kobayashi J, Tauchi H, Komatsu K. Nijmegen breakage syndrome and DNA double strand break repair by NBS1 complex. Adv Biophys. 2004;38:65-80.

12. Czapczak D, Markowska A, Piątkowska M, Friebe Z, Polaszewski A, Chechlińska $\mathrm{M}$, et al. Heterozygous germline mutations in the exon 6 of the NBS1 gene and the risk of uterine myoma journal of. Oncology. 2011;61(2):109-13.

13. Watanabe T, Nobusawa S, Lu S, Huang J, Mittelbronn M, Ohgaki H. Mutational inactivation of the Nijmegen breakage syndrome gene (NBS1) in glioblastomas is associated with multiple TP53 mutations. J Neuropathol Exp Neurol. 2009:68(2):210-5. https://doi.org/10.1097/NEN. ob013e31819724c2.

14. Sansregret L, Vanhaesebroeck B, Swanton C. Determinants and clinica implications of chromosomal instability in cancer. Nat Rev Clin Oncol. 2018; 15(3):139-50. https://doi.org/10.1038/nrclinonc.2017.198.

15. Gładkowska-Dura M, Dzierzanowska-Fangrat K, Dura WT, van Krieken JH, Chrzanowska KH, van Dongen JJ, et al. Unique morphological spectrum of lymphomas in Nijmegen breakage syndrome (NBS) patients with high frequency of consecutive lymphoma formation. J Pathol. 2008;216(3):33744. https://doi.org/10.1002/path.2418.

16. Bienemann K, Burkhardt B, Modlich S, Meyer U, Möricke A, Bienemann K, et al. Promising therapy results for lymphoid malignancies in children with chromosomal breakage syndromes (Ataxia teleangiectasia or Nijmegenbreakage syndrome): a retrospective survey. Br J Haematol. 2011;155(4):46876. https://doi.org/10.1111/j.1365-2141.2011.08863.x.

17. Dembowska-Baginska B, Perek D, Brozyna A, Wakulinska A, Olczak-Kowalczyk D, Gladkowska-Dura M, Grajkowska W, Chrzanowska KH. Non-Hodgkin lymphoma (NHL) in children with Nijmegen breakage syndrome (NBS). Pediatr Blood Cancer. 2009;52(2):186-90. https://doi.org/10.1002/pbc.21789. 
18. Pastorczak A, Szczepanski T, Mlynarski W. International Berlin-FrankfurtMunster (I-BFM) ALL host genetic variation working group. Clinical course and therapeutic implications for lymphoid malignancies in Nijmegen breakage syndrome. Eur J Med Genet. 2016;59(3):126-32. https://doi.org/10. 1016/j.jmg.2016.01.007.

19. Pastorczak A, Górniak P, Sherborne A, Hosking F, Trelińska J, Lejman M, et al. Role of 657del5 NBN mutation and 7p12.2 (IKZF1), 9 p21 (CDKN2A), 10q21.2 (ARID5B) and 14q11.2 (CEBPE) variation and risk of childhood ALL in the polish population. Leuk Res. 2011;35(11):1534-6. https://doi.org/10.1016/j. leukres.2011.07.034.

\section{Publisher's Note}

Springer Nature remains neutral with regard to jurisdictional claims in published maps and institutional affiliations.

Ready to submit your research? Choose BMC and benefit from:

- fast, convenient online submission

- thorough peer review by experienced researchers in your field

- rapid publication on acceptance

- support for research data, including large and complex data types

- gold Open Access which fosters wider collaboration and increased citations

- maximum visibility for your research: over $100 \mathrm{M}$ website views per year

At BMC, research is always in progress. 